\title{
Article
}

\section{Insights on the Mechanism of Formation of Protein Microspheres in Biphasic System}

Raquel Silva, Helena Ferreira, Nuno G. Azoia, Ulyana Shimanovich, Giuliano Freddi, Aharon Gedanken, and Artur Cavaco-Paulo

Mol. Pharmaceutics, Just Accepted Manuscript • Publication Date (Web): 01 Oct 2012

Downloaded from http://pubs.acs.org on October 12, 2012

\section{Just Accepted}

"Just Accepted" manuscripts have been peer-reviewed and accepted for publication. They are posted online prior to technical editing, formatting for publication and author proofing. The American Chemical Society provides "Just Accepted" as a free service to the research community to expedite the dissemination of scientific material as soon as possible after acceptance. "Just Accepted" manuscripts appear in full in PDF format accompanied by an HTML abstract. "Just Accepted" manuscripts have been fully peer reviewed, but should not be considered the official version of record. They are accessible to all readers and citable by the Digital Object Identifier (DOI $\left.{ }^{\circledR}\right)$. "Just Accepted" is an optional service offered to authors. Therefore, the "Just Accepted" Web site may not include all articles that will be published in the journal. After a manuscript is technically edited and formatted, it will be removed from the "Just Accepted" Web site and published as an ASAP article. Note that technical editing may introduce minor changes to the manuscript text and/or graphics which could affect content, and all legal disclaimers and ethical guidelines that apply to the journal pertain. ACS cannot be held responsible for errors or consequences arising from the use of information contained in these "Just Accepted" manuscripts.

\section{ACS Publications}




\title{
1 Insights on the Mechanism of Formation of Protein Microspheres in Biphasic System
}

\author{
3 Raquel Silva ${ }^{\dagger}$, Helena Ferreira ${ }^{\dagger}$, Nuno G. Azoia ${ }^{\dagger}$, Ulyana Shimanovich ${ }^{\dagger}$, Giuliano Freddi ${ }^{\S}$, \\ 4 Aharon Gedanken ${ }^{*}$ and Artur Cavaco-Paulo ${ }^{\dagger *}$ \\ $5 \quad \dagger$ University of Minho, Department of Textile Engineering, Campus de Azurém, 4800-058, \\ 6 \\ Guimarães, Portugal \\ $7 \quad$ Laboratory for Nanomaterials, Centre for Advanced Materials and Nanotechnology, University \\ 8 \\ of Bar-Ilan Ramat-Gan, 52900, Israel \\ 9 \\ ${ }^{\S}$ Silk Research Institute Via Giuseppe Colombo 83, 20133 Milan, Italy \\ 10 *University of Minho, Department of Textile Engineering, Campus de Azurém, 4800-058, \\ 11 Guimarães, Portugal, artur @det.uminho.pt, Tel: 00351253 510271, Fax: 00351253510293
}

12 ABSTRACT. Microspheres of bovine serum albumin (BSA) and silk fibroin (SF) are produced 13 by applying ultrasound in a biphasic system consisting of an aqueous protein solution and an 14 organic solvent. The protein microspheres are dispersed in an aqueous media where the protein 15 remains at the interface covering the organic solvent. This only occurs when high shear forces 16 are applied that induce changes to force the protein to the interface. FT-IR results indicate a large 17 increase in the content of the $\beta$-sheet during the formation of silk fibroin microspheres. 
1 Molecular dynamics' simulations show a clear adaption on 3D structure of BSA when stabilized

2 at the interface, without major changes in secondary structure. Further studies demonstrate that

3 high water content, oil solvents and larger peptides with separated and clear hydrophobic and

4 hydrophilic areas lead to more stable and smaller spheres. This is the first time that these results

5 are presented. We also present herein the rationale to produce tailored protein microspheres with

6 a controlled size, controlled charge and increased stability.

7 KEYWORDS amino acids; hydrophobic/hydrophilic balance; microspheres; proteins;

8 sonochemistry.

9 1. Introduction

10 Micro- and nano-particles have found diverse and important applications, ranging from the 11 encapsulation of dyes, flavors, and fragrances, to drug delivery systems and to the study of 12 membrane structure, function and reactivity. ${ }^{1-3}$

13 A sonochemical method has been developed by Suslick and co-workers for the synthesis of 14 non-aqueous liquid-filled microcapsules and air-filled microbubbles. ${ }^{4}$ Suslick has shown that 15 micrometer sized gas- or liquid-filled proteinaceous microspheres can be produced from various 16 kinds of proteins, such as bovine serum albumin (BSA), ${ }^{4-6}$ human serum albumin (HSA) ${ }^{7}$ and 17 hemoglobin $(\mathrm{HB}){ }^{8}$ Suslick reports on microspheres formed at high concentrations with a long 18 shelf life and high stability. The mechanism of the preparation of proteinaceous microspheres 19 obtained by the sonochemical method has been discussed previously and is a direct result of the 20 chemical effects of ultrasound irradiation on an aqueous medium. ${ }^{9}$ Indeed, microsphere 21 formation is a combination of two acoustic phenomena, emulsification and cavitation. Ultrasonic 22 emulsification creates the microscopic dispersion of the protein solution necessary to form the 
1 shape of the proteinaceous microsphere shell. On the other hand, the ultrasonic irradiation of

2 liquids produces acoustic cavitation, i.e., the formation, growth and implosive collapse of

3 bubbles. The collapse of such bubbles creates transient hot-spots with enormous peak

4 temperatures and the production of free radicals. ${ }^{10-13}$ The superoxide radical $\left(\mathrm{O}_{2}{ }^{-\bullet}\right)$ can create

5 inter-protein disulphide bonds that cross-link the proteins. ${ }^{4-8}$ However, Gedanken et al. had

6 shown that it is possible to form microspheres with proteins that did not comprise the Cysteine

7 a.a. in their structure, as streptavidin or poly (Glutamic Acid). ${ }^{14}$ According to their explanation,

8 hydrophobic interactions or thermal denaturation of the protein after the initial ultrasonic

9 emulsification assists in microsphere formation. ${ }^{14}$ However, most of those explanations were 10 speculative and lacking in experimental support.

11 In the present work our main goal was to elucidate further the previously-suggested 12 hydrophobic interactions, as well to clarify the structural changes that the protein undergoes 13 during microsphere formation.

14 For studying the structural changes in the protein due to microsphere formation under US 15 (ultrasonic waves) we chose two proteins, BSA (bovine serum albumin) protein and SF (silk 16 fibroin) protein. The reason for choosing these proteins is their secondary structure. The BSA 17 protein is a globular protein ${ }^{15}$ that mainly contains an alpha-helix component, while SF mainly 18 consists of a beta-sheet component. ${ }^{16,17}$ We expect that using proteins that have completely 19 different structures will provide us sufficient information for understanding the mechanism of 20 PM formation in a biphasic system by applying US. In a literature survey we could not find any 21 previous work reporting on such structural changes.

22 The formation of PMs was also investigated by using a wide range of peptides with variable 23 sequences, sizes and different hydrophilic/hydrophobic ratios. We therefore expect to offer new 
1 insights onto the mechanisms of the formation of PMs and a rationale the formation of controlled

2 size and controlled charged particles.

\section{2. Experimental Section}

$4 \quad 2.1$. Materials

5 Unless otherwise stated, all the solvents and reagents used in this study were commercially 6 supplied by Sigma-Aldrich and used as received. SF was donated by Dra Silvia Cappellozza 7 from "Sezione Specializzata per la Bachicoltura" (Padova). Different peptides were constructed 8 based on the fatty acid model, and on the primary sequence of a secretory leucocyte protease 9 inhibitor (SLPI). ${ }^{18}$ The peptide structures were synthesized by JPT Peptide Technologies GmbH 10 (Berlin, Germany). These peptides were supplied as a lyophilized material. They were analyzed 11 by high performance liquid chromatography (HPLC) and mass spectrometry (MS), and their 12 purity was over 70\% (HPLC, $220 \mathrm{~nm}, \mathrm{C}_{18}$, linear gradient). The same peptide aqueous solution 13 concentration $(100 \mu \mathrm{M}, \mathrm{pH} \approx 6)$ was used in the assays. For the more hydrophobic peptides it 14 was necessary to add DMSO (until 1\%) to reach the final concentration. The peptide sequence of 15 is described by a one-letter code, which is the symbol commonly used to represent the amino 16 acid (a.a.) residue (Supporting information).

\section{2.2. Equipment}

18 The experimental set up was composed of a probe-type ultrasound source $(20 \mathrm{kHz}$ Sonics \&

19 Materials Vibracell CV 33) fitted with a $3 \mathrm{~mm}$ diameter titanium micro-tip. Power delivery was 20 controlled as percentage amplitude. The reaction vessel was an open glass cell (diameter $19 \mathrm{~mm}$ 21 and height $75 \mathrm{~mm})$ containing the sample solution $(16 \mathrm{~mL})$. The sonochemical reactor 22 temperature was controlled via a thermostatted water bath with a freezer exchanger placed within 
1 a thermo jacket cell, which gave a steady operating temperature $\left(10 \pm 1^{\circ} \mathrm{C}\right)$. The temperature was

2 monitored throughout using four wire K-type thermocouples (TCs), three positioned at the outer

3 sides and one at the base of a glass vessel. The TCs were interfaced with a Pico Technology TC-

408 Thermocouple data logger connected to a computer with Pico Log software version R.33. The

5 initial temperature $\left(\mathrm{T}_{\mathrm{i}}\right)$ was taken from the average within the solution for $10 \mathrm{~s}$ prior to

6 activation, and the final temperature $\left(T_{f}\right)$ the average in the final $40 \mathrm{~s}$ of sampling. The change in

7 temperature $(\Delta \mathrm{T})$ from the initial to final levels was calculated for each $\mathrm{TC}$ position where $\Delta \mathrm{T}=$

$8 \mathrm{~T}_{\mathrm{f}}-\mathrm{T}_{\mathrm{i}}$, values were averaged from the four TC positions to give $\Delta \mathrm{T}_{\mathrm{AVE}}$.

\section{2.3. Microsphere preparation}

10 The microspheres were prepared by an adaptation of Suslick's method. Briefly, the bottom of a 11 high-intensity ultrasonic horn was positioned at the interface of the protein/peptide aqueous 12 solution and $n$-dodecane at an amplitude of $40 \%$ at $10^{\circ} \mathrm{C}( \pm 1)$ for $3 \mathrm{~min}$. The ratios of 13 aqueous/organic phase (\%) used were: $95 / 5,80 / 20$ and $60 / 40$, and for each of these ratios the 14 following concentrations of BSA were employed: $0.1 ; 0.5 ; 1.0$ and $5.0 \mathrm{~g} \mathrm{~L}^{-1}$. For SF, for each 15 aqueous/organic ratio, the following amounts were used: $1.0 ; 3.0 ; 5.0$ and $10.0 \mathrm{~g} \mathrm{~L}^{-1}$.

16 To obtain a complete separation of the protein/peptide microspheres from the mother solution, 17 the flasks were placed in a refrigerator $\left(4{ }^{\circ} \mathrm{C}\right)$ for $24 \mathrm{~h}$, after which the microspheres were 18 collected by centrifugation (2000 g, $30 \mathrm{~min}$.) using the centricon tubes (molecular weight cut-off 19 of 100 and $3 \mathrm{kDa}$, Amicon) in order to separate them from the protein/peptide mother solution.

20 2.4. Scanning transmission electron microscopy (STEM)

21 For STEM analysis, the diluted microsphere suspension was dropped on copper grids with a 22400 mesh carbon film, $3 \mathrm{~mm}$ in diameter. The shape and morphology of the microspheres were 23 observed using a NOVA Nano SEM 200 FEI instrument. 


\subsection{Confocal microscopy}

For the confocal measurements, Nile Red with concentration of $105 \mu \mathrm{M}$ was added to the organic solvent. The samples were analyzed with a confocal laser scanning microscope, Leica

TCS SPE. For the three-dimensional (3D) reconstruction, Imaris software was used (version 7.0, Bitplane, Zurich).

\subsection{FT-IR analysis}

Infrared spectra were recorded at room temperature using a Perkin Elmer Spectrum 100 Infrared spectrophotometer from $4000 \mathrm{~cm}^{-1}$ to $500 \mathrm{~cm}^{-1}$. To eliminate spectral contributions due to atmospheric water vapour, the instrument was continuously purged with dry air. The protein microsphere emulsion was quickly transferred to a potassium bromide $(\mathrm{KBr})$ Liquid Omni Windows support cell in an Omni Cell Assembly accessory, specially designed for liquid solutions. All samples were measured at least three times. A Gaussian deconvolution of an Amide I band region was performed using OriginPro 8.5 software. The number of components and their peak position were determined from the second derivative spectrum of the same region. The secondary structure content was calculated from the areas of the assigned peak as a percentage fraction of the total area of the Amide I range. For all the data, a linear baseline was fitted and self-deconvolution was performed using a Gaussian function.

2.7. Molecular studies of protein/peptide interaction between the aqueous and the organic phase

Molecular dynamics' simulations were performed with the GROMACS package, using the GROMOS96 force field with an integration time step of $2 \mathrm{fs}$. Bond lengths were constrained with LINCS for the solute and with SETTLE for the water. Non-bonded interactions were calculated using a twin-range method with short and long range cut-offs of 8 and $14 \AA$, 
1 respectively. An SPC water model was used. The solute and solvent were coupled to two

2 separate heat baths with temperature coupling constants of $0.1 \mathrm{ps}$ and reference temperatures of

$3300 \mathrm{~K}$. The pressure control was implemented with a reference pressure of $1 \mathrm{~atm}$ and a relaxation

4 time of $0.5 \mathrm{ps}$. The results represent $50 \mathrm{~ns}$ of simulated time. The number of $n$-dodecane

5 molecules was chosen so that the final solution would be equivalent to a $1: 1$ mixture of water $/ n$ -

6 dodecane (v/v).

$7 \quad$ 2.8. Microsphere yield

8 The efficiency of microsphere formation was assessed via the Lowry method, ${ }^{19}$ a method

9 based on the quantification of protein/peptides in supernatant. This method was performed to 10 quantify the protein/peptide in supernatant, using BSA as standard protein. The total protein 11 concentration is exhibited by a colour change of the sample solution in proportion to 12 protein/peptide concentration, which can then me measured by calorimetric techniques. The 13 absorbance was measured at $750 \mathrm{~nm}$, using the Heגios y spectrometer (Unicam). The efficiency 14 of microsphere formation was calculated according to Eq. (1):

15 Microspheres formation $(\%)=\frac{[\mathrm{P}]_{\mathrm{i}}-[\mathrm{P}]_{\mathrm{f}}}{[\mathrm{P}]_{\mathrm{i}}} \times 100$,

16 where $[\mathrm{P}]_{\mathrm{i}}$ and $[\mathrm{P}]_{\mathrm{f}}$ are the initial and the final protein/peptide concentration in the aqueous 17 solution, respectively. This process indicates the percentage of protein/peptide microspheres in 18 relation to the initial amount of protein/peptide. Measurements were recorded in triplicate and 19 the results were expressed as mean value \pm standard deviation.

20 2.9. Size and zeta-potential determinations

21 The zeta-potential and the size distribution of microspheres were determined at $25.0 \pm 0.1{ }^{\circ} \mathrm{C}$ 22 using a Malvern zetasizer NS (Malvern Instruments) with an electrophoretic laser Doppler 23 anemometry and photon correlation spectroscopy (PCS), respectively. The protein/peptides were 
1 diluted in distilled water to $1: 100$, and in order to verify the reproducibility of the preparation of

2 the microspheres assembled under the typical process described above, the procedure was carried

3 out at least three times for each individual particle. The results were expressed as a mean value \pm

4 standard deviation.

$5 \quad 2.10$. Microsphere stability

6 The microspheres were stored at $4{ }^{\circ} \mathrm{C}$ over four months. The stability of the microspheres was 7 measured in terms of size distribution, zeta-potential and the macroscopic aspect. The 8 measurements of size and zeta-potential were done every week by the procedure previously 9 described. The procedure was carried out at least three times for each individual particle. The 10 instability of the microspheres was verified when there was a variation of $5 \%$ in the size and 11 zeta-potential.

12 3. Results and Discussion

$13 \quad 3.1$ Protein microspheres formation

14 Both types of proteins (BSA and SF) were successfully converted to PMs by using high 15 intensity ultrasound, verified by STEM results (Figure 1). Figure 1 illustrates that these PMs are 16 clearly spherical particles with smooth surfaces. The morphology of spherical shapes would offer 17 the highest potential for the controlled release and protection of incorporated drugs, as they 18 provide minimum contact with the aqueous environment, as well as the longest diffusion 19 pathways. Comparing the particles with any other-shaped spherical particles also requires the 20 smallest amount of surface-active agent for stabilization because of their small specific surface 21 area. $^{20}$ Furthermore, the results are evidence of a more homogeneous population for BSA 22 microspheres when compared to SF microspheres. 

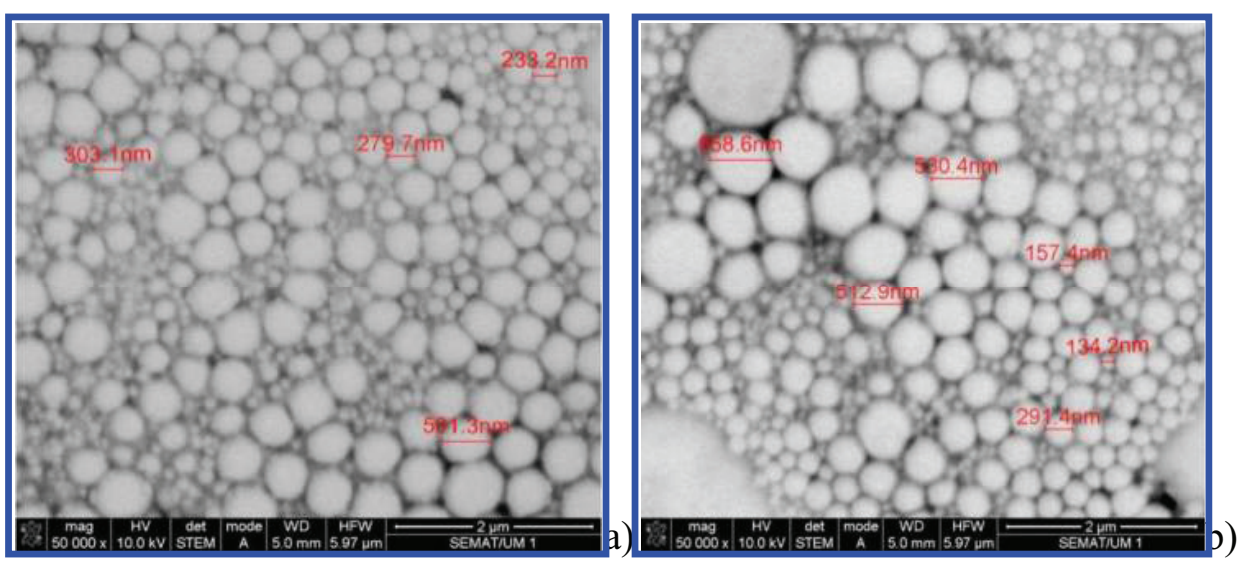

2 Figure 1. STEM photographs (x50000 magnification) of proteinaceous microspheres: (a) BSA

3 and (b) SF obtained with a protein concentration of $5.0 \mathrm{~g} \mathrm{~L}^{-1}$ and $10.0 \mathrm{~g} \mathrm{~L}^{-1}$ for BSA and SF, 4 respectively.

5 A lipophilic fluorescent probe was incorporated into PMs and analyzed by confocal 6 microscopy, providing a refined data set and, ultimately, a more precise evaluation of protein 7 arrangement (Figure 2). Nile red is a dye that exhibits solvatochromism and its absorption band 8 varies in its spectral position, shape and intensity, with the nature of the solvent. The dye is 9 highly fluorescent in organic solutions, and increasing the polarity of the solvent leads to an 10 enhancement of emission and excitation maxima when the fluorescent spectra are measured. ${ }^{21,22}$ 11 Figure 2 emphasizes the protein behavior at an aqueous/organic interface, presenting a green 12 color in a less hydrophobic medium, while in a nonpolar solvent it acquires a red color. The 13 results clearly demonstrate the protein arrangement in microparticle formation, suggesting a 14 more hydrophobic core in its structure. 

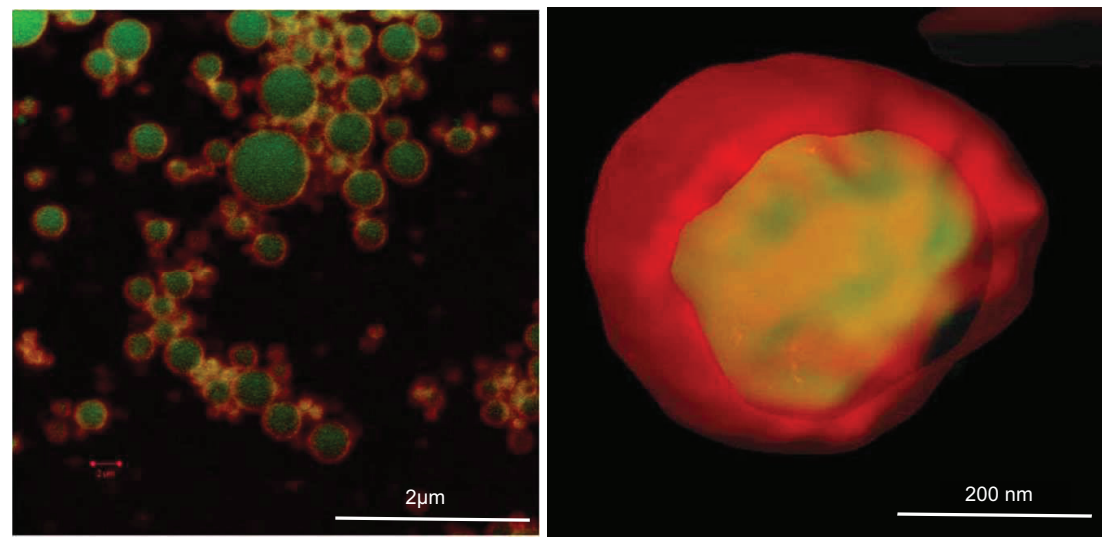

2 Figure 2. Left: Confocal photograph of BSA microspheres colored with Nile red dye (green

3 color shows the more polar regions excited with a laser line of $532 \mathrm{~nm}$, and the red color shows

4 the more nonpolar regions excited with a laser line of $488 \mathrm{~nm}$ ). Right: The 3D image

5 reconstructed from confocal z-stack images using "Imaris" software, 3D evidence of the protein

6 behavior at an aqueous/organic interface, presenting a green color in a less hydrophobic medium,

7 while in a nonpolar solvent it acquires a red color, suggesting a more hydrophobic core in its

8 structure. The few green color points in the core are probably due to the water molecule trapped

9 inside the PMs.

In order to verify the mechanism of formation of the microspheres, a fundamental question that 11 arises is if the protein structure suffers a change in the microsphere arrangement. The impact of 12 conformational changes was never invoked in the mechanism formation of microspheres 13 obtained by ultrasound. Herein, we report the conformational changes in secondary structures of 14 BSA and SF after microsphere formation by ultrasound irradiation using the FT-IR assessment.

15 The characteristic bands found in the infrared spectra of proteins and polypeptides include 16 Amide I, Amide II and Amide III. These vibrational bands arise from the amide bonds (-CONH-)

17 that link the a.a.. The absorption associated with the Amide I vibrational band is assigned to 18 stretching vibrations of the $\mathrm{C}=\mathrm{O}$ bond of the Amide and is detected in the range of 1700- 
$11600 \mathrm{~cm}^{-1}-^{23,24}$ In this work a deeper study on the Amide I band was conducted to probe the

2 microspheres' secondary structure. The Fourier deconvolution procedure, sometimes referred as

3 "resolution enhancement," involves narrowing the widths of infrared bands, thus allowing an

4 increased separation of the overlapping components present within the broad band envelope. ${ }^{25-27}$

5 BSA is a globular protein and its secondary structure consists mainly of $\alpha$-helices. ${ }^{28-31}$ For SF-

6 untreated samples, Silk I (Random coil) conformation is confirmed by intense bands at 1411,

7 1380, $1334 \mathrm{~cm}^{-1}$, which are considered marker bands for this structure. ${ }^{32}$ Table 1 presents

8 detailed information on Amide I deconvolution for BSA and SF microspheres. In this

9 approach, the Amide I band was transformed to yield a fitted self-deconvoluted set of bands

10 from which the secondary structure was determined (Supporting Information, Figure S1 and S2).

11 BSA microspheres presented a similar $\alpha$-helix content in their structure, and the microsphere

12 synthesis by the sonochemical method apparently did not disturb the integrity of the secondary

13 protein structure. On the other hand, for SF the deconvolution resulted in an increase in the $\beta$ -

14 sheet content. This data indicate that through microsphere formation, SF acquires mainly a $\beta$ -

15 sheet conformation, induced by microsphere formation. As a consequence of the sonochemical

16 process, the molecular distance between the molecular chains decreased, thus increasing the

17 interactions of the side chain groups and promoting a higher aggregation in the microsphere

18 formation. The FT-IR results show that the secondary structure of the fibrous protein was

19 changed, while the globular proteins retain their relative amounts of secondary structure during

20 particle formation.

21 Table 1. Results from the curve fitting of the Amide I range of the FT-IR spectrum of 22 proteinaceous microspheres prepared with $5.0 \mathrm{~g} \mathrm{~L}^{-1}$ of BSA and $10.0 \mathrm{~g} \mathrm{~L}^{-1}$ of SF, using $60 / 40$ of 23 aqueous/organic ratio 


\begin{tabular}{lllll}
\cline { 2 - 4 } & \multicolumn{3}{l}{ BSA } & \\
\cline { 2 - 5 } & Untreated $^{[\mathrm{a}]}$ & Microsphere & Untreated $^{[\mathrm{b}]}$ & Microsphere \\
\hline$\beta$-Sheet & $48-32 \%$ & $\approx 39 \%$ & $\approx 29 \%$ & $\approx 59 \%$ \\
\hline$\alpha$-Helix & $52-68 \%$ & $\approx 61 \%$ & - & - \\
\hline $\begin{array}{l}\text { Random } \\
\text { coil/Silk }\end{array}$ & - & - & $\approx 43 \%$ & $\approx 15 \%$ \\
I & & & \\
\hline $\begin{array}{l}\text { Turns } \\
\text { and } \\
\text { bends }\end{array}$ & - & - & & \\
\hline
\end{tabular}

1 [a] Based on literature values ${ }^{28-30}$ [b] Based on our group's previously published results of ${ }^{32}$

2 To assess the behavior of a globular protein, BSA, through an ultrasound system, a molecular 3 modeling study was performed using GROMACS software ${ }^{33}$ with the GROMOS (ffG53A6)

4 force-field. ${ }^{34}$ The sonication process was not easily simulated, but to obtain some realistic model, 5 the $n$-dodecane molecules were added randomly and the empty space was filled with water. The 6 procedure, where all the components are randomly distributed through space, seems to be the 7 best approach to simulate the sonication process. Figure 3 shows BSA in the interface between 8 water and $n$-dodecane. The protein retains some water molecules in the surface interacting with $9 n$-dodecane. However, it demonstrates a preferential orientation towards the interface. 
1

2 Figure 3. Molecular dynamic simulation results of BSA in a $1: 1$ (v:v) mixture of water $/ n$ -

3 dodecane. BSA (green) in the interface water (red and white) $/ n$-dodecane (not shown). The BSA

4 portion that is visible is interacting with $n$-dodecane.

$5 \quad$ Figure 4 illustrates the differences between the BSA surfaces in terms of potential. It is clear 6 that the surface interacting with $n$-dodecane is more hydrophobic (the surface potential is near 7 zero). In contrast, the surface interacting with water clearly has a negative surface potential.

8 Molecular dynamics suggest that BSA can adapt their tertiary structure at the interface 9 aqueous/organic solvent stabilizing the microspheres, probably leading to smaller particles. No 10 significant changes were found in the secondary structure, as shown by FT-IR results. SF shows 11 an enhancement of ordering, promoting a more rigid structure; consequently higher sizes are 12 observed. Furthermore, this evidence shows that the protein structure suffers an alteration in the 13 interface, promoting the microspheres' stability. 


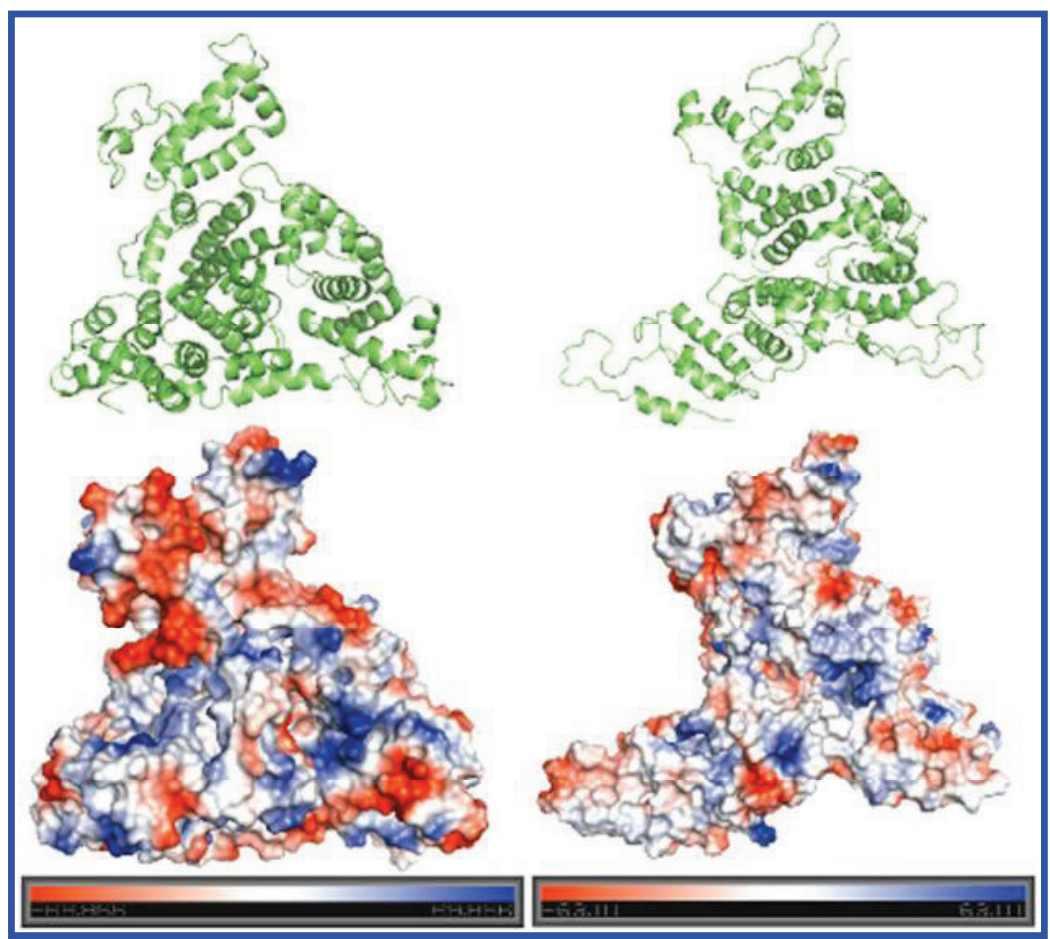

2 Figure 4. Representation of the potential surface in vacuum: left) on the surface of BSA facing

3 the water phase; right) on the surface of BSA that lies on the interface water $/ n$-dodecane. The

4 potentials were calculated using Pymol.

5 Other important question in this study is whether the effect of protein concentration and the

6 ratio of aqueous/organic (water/ $n$-dodecane) disturb the PMs. By varying these parameters it was

7 possible to establish how they interfere in the physico-chemical of PMs. SF concentrations were

8 higher than BSA concentrations, because at concentrations below $3.0 \mathrm{~g} \mathrm{~L}^{-1}$ of SF we could not

9 obtain microspheres. This phenomenon can be related to the spherization process, in which the

10 protein tends to move to the interface to form the particles. The microsphere formation occurs

11 only when the protein concentration exceeds a threshold which could be called a concentration

12 above which spheres are formed. This concentration barrier is similar to the well-known critical

13 micelle concentration (CMC). Considering this explanation, one may anticipate that the proteins 
1 would be dispersed in a solution below a critical concentration, and will only start to form

2 microspheres at or above this concentration.

3 The effects of protein concentrations and the different aqueous/organic phase ratios used on

4 microsphere formation were studied. The results demonstrated that as the concentration of the

5 protein increases, the yield of the microspheres increases, reaching the maximum yield near to

$6 \quad 100 \%$ at concentration of $5.0 \mathrm{~g} \mathrm{~L}^{-1}$ and $10.0 \mathrm{~g} \mathrm{~L}^{-1}$ for BSA and SF, respectively (Figure 5).

7 Conversely, for lower concentrations of proteins, the yield obtained was significantly different

8 for ratios of $80 / 20$ compared to the $95 / 5$ aqueous/organic ratio.

9

10

11 aqueous/organic ratios $(\% ; 60 / 40 ; 80 / 20$ and $95 / 5)$ and different protein concentrations $(0.1 ; 0.5$;

$12 \quad 1.0 ; 5.0 \mathrm{~g} \mathrm{~L}^{-1}$ for BSA and 3.0; $5.0 ; 10.0 \mathrm{~g} \mathrm{~L}^{-1}$ for $\mathrm{SF}$ ).

13 These results for the PMs obtained with lower protein concentrations $\left(0.1,0.5\right.$, and $1.0 \mathrm{~g} \mathrm{~L}^{-1}$ 14 for BSA and 3.0, and $5.0 \mathrm{~g} \mathrm{~L}^{-1}$ for SF) can be explained by the low frequency of the collision of 15 BSA and SF molecules and the density of the microparticle membrane, which decreases the yield 16 of the microspheres obtained. The influence of the $n$-dodecane volume fraction on the 17 microsphere formation yield becomes remarkable only when lower protein concentrations are 18 used. For these amounts a higher content of $n$-dodecane promotes the higher efficiency of 
1 particle formation. This assay further suggests that for the more concentrated protein solutions,

2 the yield was approximately $100 \%$ for all the ratios tested.

3 The formation of protein microspheres from a water/organic solvent biphasic system is not an

4 equilibrium event, since protein can suffer a change in conformation induced by ultrasound, as

5 shown above in this report. However, the adsorption/bonding of protein at the interface of the

6 microspheres can be described by a mathematical relationship associated with a similar isotherm

7 model. In order to understand the amount $(\mathrm{g})$ of protein in spheres versus the size, the BET

8 isotherm was applied. The simplified BET isotherm (2) showed good agreement with our data.

$9 \quad \frac{\mathrm{n}_{\mathrm{a}}}{\mathrm{n}_{\mathrm{m}}}=\frac{1}{1-\mathrm{x}}$,

10 where, $n_{a}$ is the adsorbed amount, $n_{m}$ is the amount of protein solute required to form a 11 monolayer of the adsorbate and $\mathrm{x}$ is the relative concentration $(\mathrm{C} / \mathrm{Co}$, where the $\mathrm{C}$ is the final 12 concentration of protein/peptide in the microsphere and Co is the initial concentration of 13 protein/peptide). $\mathrm{n}_{\mathrm{m}}$ values were achieved by nonlinear regression fit of equation (2) to the 14 experimental data of $\mathrm{n}_{\mathrm{a}}$ versus $\mathrm{x}$. The $\mathrm{n}_{\mathrm{a}}$ is the quantity $(\mathrm{g})$ of protein in the microspheres, 15 previously obtained by Lowry method.

16 We can expect that several layers of protein can be adsorbed at the oil interface, which can be 17 well described by the simplified BET isotherm concept.

18 The exact values of the obtained PM sizes versus initial protein concentration and 19 water/organic solvent ratio are summarized in Table 2 and Table 3. These tables, followed by 20 Figure 6 (changes in BSA and SF PMs size as a result of the different initial concentration of 21 proteins), highlight the fact that when a lower quantity of the organic phase is used it is possible 22 to obtain a narrower size distribution of PMs with a smaller size (nanometer level). Moreover, 23 the stability of created BSA and SF PMs as a function of size, concentration and water/organic 
1 solvent ratio charges was studied and presented in Table 2 and Table 3. BSA clearly has a lower

2 critical spherization concentration, leads to small size particles and presents lower amounts of

3 proteins at the interface when compared with SF.

4 Table 2. Protein in monolayer, size (Z-average), particle size distribution (PDI) and stability 5 tests at the end of 4 months, obtained for the BSA protein $\left(5.0 \mathrm{~g} \mathrm{~L}^{-1}\right)$

\begin{tabular}{lllll}
\hline $\begin{array}{l}\text { Aqueous/organic } \\
\text { ratio }\end{array}$ & $\begin{array}{l}\text { Monolayer } \\
\left(\mathrm{n}_{\mathrm{m}}\right)^{[\mathrm{a}]}\end{array}$ & $\begin{array}{l}\text { Z- } \\
\text { average } \\
{[\mathrm{d} . \mathrm{mm}]}\end{array}$ & PDI & $\begin{array}{l}\text { Stability } \\
{[\mathrm{mg}]}\end{array}$ \\
\hline $60 \mathrm{week}]$ \\
\hline $80 / 40$ & $0.022 \pm 0.01$ & $1039 \pm 127$ & $0.86 \pm 0.02$ & 16 \\
\hline $95 / 5$ & $1.40 \pm 0.05$ & $577 \pm 15$ & $0.44 \pm 0.04$ & 12 \\
\hline
\end{tabular}

$6 \quad$ [a] Calculated according with Eq. (2)

7 Table 3. Protein in monolayer, size (Z-average), particle size distribution (PDI) and stability

8 tests at the end of 4 months, obtained for the SF protein $\left(5.0 \mathrm{~g} \mathrm{~L}^{-1}\right)$

\begin{tabular}{lllll}
\hline $\begin{array}{l}\text { Aqueous/organic } \\
\text { ratio }\end{array}$ & $\begin{array}{l}\text { Monolayer } \\
\left(\mathrm{n}_{\mathrm{m}}\right)^{[\mathrm{a}]} \\
{[\mathrm{mg}]}\end{array}$ & $\begin{array}{l}\text { Z- } \\
\text { average } \\
{[\mathrm{d} . \mathrm{nm}]}\end{array}$ & PDI & $\begin{array}{l}\text { Stability } \\
{[\text { week] }}\end{array}$ \\
\hline $60 / 40$ & $1.05 \pm 0.01$ & $1505 \pm 194$ & $0.69 \pm 0.02$ & 16 \\
\hline $80 / 20$ & $1.82 \pm 0.04$ & $964 \pm 100$ & $0.68 \pm 0.01$ & 6 \\
\hline $95 / 5$ & $9.30 \pm 0.1$ & $723 \pm 76$ & $0.47 \pm 0.02$ & 6 \\
\cline { 2 - 5 } & \multicolumn{1}{c}{ [a] Calculated according with Eq. (2) } & &
\end{tabular}

$9 \quad$ [a] Calculated according with Eq. (2) 


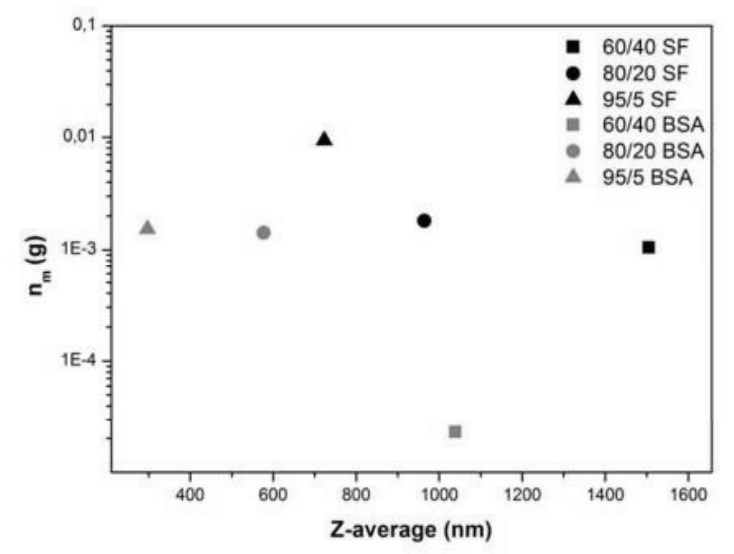

1

2 Figure 6. Relationship between the protein present in the monolayer of microsphere $\left(\mathrm{n}_{\mathrm{m}}, \mathrm{g}\right)$,

3 calculated from Eq. (2) and the size obtained (nm).

4 The microspheres were prepared in water, consequently the ionizable groups can dissociate,

5 leaving charges on microspheres, determined by zeta-potential measurements. The data obtained

6 showed that, independent of the aqueous/organic ratio and the concentrations used, they present

7 a negative surface charge. Their zeta-potential values were slightly varied around $-45 \mathrm{mV}$ and -

$838 \mathrm{mV}$ at the BSA and SF suspensions, respectively. In most circumstances, the higher the

9 absolute value of the zeta-potential of the microspheres, the larger was the amount of charge on

10 their surface. This produces stronger repellent interactions among the microspheres dispersed in

11 the buffer/water, thus resulting in higher stability. ${ }^{35}$

12 As colloidal particles can suffer aggregation over time, ${ }^{36}$ we carried out measurements of

13 particle size over a period of four months to assess their physical stability. The zeta-potential was

14 also determined, since this parameter of colloidal particles, due to degradation of some 15 components, can also change over storage time. ${ }^{37}$

16 The results of the investigation of the stability of PMs versus the different initial concentration

17 of protein and water/organic solvent ratio are presented in Tables 2 and 3. We observe that an 
1 increase in size higher than 5\% is accompanied by a change in the zeta-potential (values close to

2 zero). This change is indicative of microsphere instability. The data obtained (Tables 2 and 3)

3 demonstrate the high stability of the microspheres using the highest protein concentration.

4 When comparing the different fractions of the organic phase it was observed that the 5 microspheres obtained with 5 and $20 \%$ of $n$-dodecane, aggregate after twelve weeks of storage 6 for BSA microspheres and six weeks of storage for SF microspheres. An increase in BSA 7 microsphere size (Z-average) was observed as follows: $577 \pm 15$ to $700 \pm 50 \mathrm{~nm}$ and $297 \pm 11$ to $8400 \pm 20 \mathrm{~nm}$ for $80 / 20$ and $95 / 5$ of aqueous/organic ratio, respectively. The stability results also 9 demonstrated the tendency of the zeta-potential to attain lower negative zeta-potential values ($1030 \pm 4 \mathrm{mV}$ and $-20 \pm 2 \mathrm{mV}$ for $80 / 20$ and $95 / 5$ of aqueous/organic ratios, respectively). Similar data 11 was obtained for SF microspheres, where an increase in size was observed: $964 \pm 100$ to $121020 \pm 97 \mathrm{~nm}$ and $723 \pm 76$ to $870 \pm 90 \mathrm{~nm}$ for $80 / 20$ and $95 / 5$ of aqueous/organic ratio, 13 respectively. Furthermore, the zeta-potential values instigated signs of instability, presenting a 14 significant change in the measurements that were performed $(-14 \pm 1 \mathrm{mV}$ and $-10 \pm 3 \mathrm{mV}$ for $80 / 20$ 15 and $95 / 5$ of aqueous/organic ratios, respectively).

16 When considering these results, it is possible to conclude that microspheres prepared with $60 / 40$ 17 of the aqueous/organic phase and with highest amount of protein $\left(5.0 \mathrm{~g} \mathrm{~L}^{-1}\right.$ and $10.0 \mathrm{~g} \mathrm{~L}^{-1}$ for BSA 18 and SF, respectively) are stable for at least four months.

19 3.2. Effect of different amino acids residues on microspheres formation

20 In order to identify a strategy that provided an acceptable mechanism for microsphere 21 formation, we sought to extend the sonochemical methodology to several synthetic peptides. The 22 study with peptides was first performed using ten different hexapeptides with the general 23 sequence of GXGXGX, where G is Glycine and X can be Alanine, Serine, Leucine or Aspartic 
1 Acid. Our aim was to evaluate the effects of the chemical environment on microsphere formation

2 in this small peptide. The results proved that only the peptide with highly hydrophobic residues,

3 like Leucine, form microspheres (approximately $900 \mathrm{~nm}$ in diameter and with a PDI of $0.8 \pm 0.05$,

4 presenting a $60 \%$ yield and a negative charge). Alanine restricts the small hexapeptide ability to

5 form microspheres at the solvent-water interface, because it was not sufficiently hydrophobic.

6 Alanine has a smaller side chain when compared with Leucine.

7 The design of the peptide motifs with a variety of sizes, charges and hydrophobicity was based 8 on the fatty acid model, which has a charged/polar head and an hydrophobic tail. The peptides 9 had the general formula of $[\mathrm{D}]_{\mathrm{x}} \mathrm{AA}[\mathrm{GAAAA}]_{\mathrm{y}}$ with 8-31 residues, with the $\mathrm{N}$-terminus linked to 10 Aspartic Acid ( $\mathrm{x}=1-4$ residues) and a tail of hydrophobic a.a. (Alanine corresponds to A; 6-18 11 residues), which is interspersed with $\mathrm{G}$ for increased flexibility. The data of Table 4 show that 12 the amount of Aspartic Acid at the $N$-terminal leads to an increase in the yield of microsphere 13 formation to smaller sizes and to highly charged microspheres. It is known that highly charged 14 particles can produce more stable microspheres due to their inter-negative repulsive interactions. 15 Furthermore, the increased size of the hydrophobic tail of the GAAAA motif also promotes the 16 enhancement of the yield of microsphere formation, a decrease in size values, and high 17 monodispersed fractions. These results indicate that the peptides with concentrated charged areas 18 and clear, larger hydrophobic regions lead to smaller sizes and high surface charges, thus 19 improving the microsphere formation yield and microsphere stability. 
1 Table 4. Peptide in monolayer, size (Z-average), particle size distribution (PDI), zeta-potential

$2(\zeta)$ and stability tests obtained for the engineered peptides based on fatty acid model $(100 \mu \mathrm{M})$,

3 using an aqueous/organic ratio of $60 / 40$

\begin{tabular}{|c|c|c|c|c|c|c|}
\hline $\begin{array}{l}\text { Peptide } \\
(\mathrm{N} \rightarrow \mathrm{C} \text {-terminus })\end{array}$ & $\begin{array}{l}\text { Monolayer } \\
\left(\mathrm{n}_{\mathrm{m}}\right)^{[\mathrm{a}]} \\
{[\mathrm{mg}]}\end{array}$ & $\begin{array}{l}\text { Yield } \\
{[\%]}\end{array}$ & $\begin{array}{l}Z \text { - } \\
\text { average } \\
\text { [d.nm] }\end{array}$ & PDI & $\zeta[\mathrm{mV}]$ & $\begin{array}{l}\text { Stability } \\
\text { [week] }\end{array}$ \\
\hline [D]AA[GAAAA] & $0.452 \pm 0.1$ & $49 \pm 9$ & $672 \pm 37$ & $0.6 \pm 0.03$ & $-14 \pm 1$ & 4 \\
\hline$[\mathrm{D}]_{2} \mathrm{AA}[\mathrm{GAAAA}]$ & $0.658 \pm 0.05$ & $60 \pm 4$ & $620 \pm 36$ & $0.5 \pm 0.03$ & $-26 \pm 2$ & 4 \\
\hline$[\mathrm{D}]_{3} \mathrm{AA}[\mathrm{GAAAA}]$ & $0.863 \pm 0.1$ & $68 \pm 4$ & $633 \pm 32$ & $0.6 \pm 0.07$ & $-37 \pm 1$ & 4 \\
\hline$[\mathrm{D}]_{4} \mathrm{AA}[\mathrm{GAAAA}]$ & $1.00 \pm 0.2$ & $70 \pm 3$ & $533 \pm 17$ & $0.6 \pm 0.06$ & $-39 \pm 1$ & 4 \\
\hline$[\mathrm{D}] \mathrm{AA}[\mathrm{GAAAA}]_{5}$ & $2.64 \pm 0.2$ & $89 \pm 4$ & $469 \pm 15$ & $0.4 \pm 0.04$ & $-38 \pm 3$ & 16 \\
\hline$[\mathrm{D}]_{4} \mathrm{AA}[\mathrm{GAAAA}]_{5}$ & $3.42 \pm 0.3$ & $98 \pm 1$ & $455 \pm 14$ & $0.4 \pm 0.04$ & $-47 \pm 4$ & 16 \\
\hline
\end{tabular}

$4 \quad$ [a] Calculated according with Eq. (2)

5 In the next set of experiments peptide motifs were used based on the primary sequence of a

6 secretory leukocyte protease inhibitor (SLPI, with the common potential inhibitory capacity of

7 the human neutrophil elastase (HNE). ${ }^{18}$ To maintain the size of the peptide, the four Cysteine

8 residues were replaced with a range of hydrophilic and hydrophobic residues (Table 5). 
1 Table 5. Peptide in monolayer, size (Z-average), particle size distribution (PDI), zeta-potential

$2(\zeta)$ and stability tests obtained for the engineered peptides based on SLPI sequence, $(100 \mu \mathrm{M})$,

3 using an aqueous/organic ratio of $60 / 40$

\begin{tabular}{|c|c|c|c|c|c|c|}
\hline $\begin{array}{l}\text { Peptide }^{[\mathrm{a}]} \\
(\mathrm{N} \rightarrow \mathrm{C} \text {-terminus })\end{array}$ & $\begin{array}{l}\text { Monolayer } \\
\left(\mathrm{n}_{\mathrm{m}}\right)^{[\mathrm{b}]} \\
{[\mathrm{mg}]}\end{array}$ & $\begin{array}{l}\text { Yield } \\
{[\%]}\end{array}$ & $\begin{array}{l}Z \text { - } \\
\text { average } \\
\text { [d.nm] }\end{array}$ & PDI & $\zeta[\mathrm{mV}]$ & $\begin{array}{l}\text { Stability } \\
\text { [week] }\end{array}$ \\
\hline $\begin{array}{l}\text { KRCCPDTCGIKELD } \\
\text { (PCyst) }\end{array}$ & $1.96 \pm 0.1$ & $84 \pm 2$ & $380 \pm 20$ & $0.5 \pm 0.01$ & $-26 \pm 3$ & 16 \\
\hline $\begin{array}{l}\text { KRSSPDT } \underline{S} G I K \underline{S} L D \\
\text { (PSer) }\end{array}$ & $1.74 \pm 0.05$ & $78 \pm 1$ & $971 \pm 28$ & $0.8 \pm 0.01$ & $-16 \pm 2$ & 4 \\
\hline $\begin{array}{l}\text { KRYYPDTYYGIK } \underline{Y L D} \\
\text { (PTyr) }\end{array}$ & $2.07 \pm 0.2$ & $77 \pm 0.4$ & $829 \pm 25$ & $0.8 \pm 0.02$ & $-24 \pm 1$ & 4 \\
\hline $\begin{array}{l}\text { KRㅜHPDT } \underline{H G I K \underline{H L D}} \\
\text { (PHis) }\end{array}$ & $1.93 \pm 0.1$ & $76 \pm 0.9$ & $840 \pm 13$ & $0.7 \pm 0.06$ & $+23 \pm 3$ & 4 \\
\hline $\begin{array}{l}\text { KRFFPDTFGIKFLLD } \\
\text { (PPhe) }\end{array}$ & $2.39 \pm 0.03$ & $92 \pm 0.6$ & $310 \pm 15$ & $0.5 \pm 0.03$ & $-20 \pm 1$ & 16 \\
\hline $\begin{array}{l}\text { KRLLPDTLGIKLLD } \\
\text { (PLeu) }\end{array}$ & 2.18 & $91 \pm 1$ & $300 \pm 8$ & $0.4 \pm 0.04$ & $-26 \pm 3$ & 16 \\
\hline
\end{tabular}

\section{4 [a] Changed a.a. are underline [b] Calculated according with Eq. (2)}

5 In each peptide motif, the four Cysteine residues (PCyst) were replaced by Serine (PSer),

6 Tyrosine (PTyr), Histidine (PHis), Phenylalanine (PPhe) or Leucine (PLeu). The results reported

7 in Table 5 indicate slight differences in the peptide present in the monolayer. It was confirmed

8 that Cysteine has no need for microspherization and that mass transfer is the major cause for

9 microsphere formation. The insertion of polar and basic residue in a peptide segment interferes

10 with the balance of the hydrophobic/hydrophilic character leading, to an increase in the size of

11 the microspheres. The peptide with Histidine presents positive values due to the high quantity of

12 basic Histidine residue in the sequence. 
1 The evaluation of the suspension stability of microspheres was performed by measuring the

2 size distribution, the surface charge, and observing the macroscopic aspect over four months.

3 Since these colloidal particles tend to suffer aggregation over time, particularly when stored in an

4 aqueous dispersion, as just stated, an evaluation of the particle size was done for four months,

5 aimed at evaluating their physical stability. ${ }^{36}$ The stability results showed that the peptides based

6 on fatty acid molecules model (Table 4), can form microspheres with high stability. The degree

7 of hydrophobicity of peptide motifs can significantly affect these data. When hydrophobic

8 residues increase $(y=5)$, the molecules have a tendency to assemble and form peptide matrices

9 with enhanced strength. The $[\mathrm{D}]_{1} \mathrm{AA}[\mathrm{GAAAA}]_{5}$ and $[\mathrm{D}]_{4} \mathrm{AA}[\mathrm{GAAAA}]_{5}$ peptides revealed the

10 same behavior over four months. The size distribution and the zeta-potential values were very

11 similar and there was no change in the macroscopic appearance. In contrast, the calculations for 12 the stability of the other peptides demonstrated an increase in the values of size distribution 13 higher than $5 \%$, relative to the initial size. Furthermore, the zeta-potential values tend towards 14 zero, exhibiting instability. The results indicated that the longer the peptide segment, the greater 15 is the tendency to self-assemble into well-defined and stable microstructures. The stability results 16 for PSer, PHis and PTyr, derived from SLIPI were also evaluated and an increase in the size 17 distribution ( $10 \%$ above the initial size) was observed after four weeks of storage (Table 5). 18 Additionally, the zeta-potential value, in the same period of time, was closer to zero, indicating 19 the tendency of the particles to aggregate. Conversely, for the PPhe and PLeu, the values 20 obtained for size distribution and zeta-potential, during four months were very similar. The 21 results achieved are mainly due to the presence of Cysteine and hydrophobic residues. The 22 Cysteine allows the disulphide bonds between those residues in adjacent peptides to induce 
1 robust covalent bonds. Furthermore, the hydrophobicity of the Phenylalanine and Leucine groups

2 prove sufficient to promote stable microdevices.

3 To confirm the influence of different poly (amino acids) on microsphere formation, poly

4 (Lysine); poly (Serine); poly (Proline); and poly (Alanine) were tested. Table 6 shows that only 5 poly (Lysine) did not form microspheres. The polarity and the positive charge of Lysine could 6 compromise microsphere formation. The best result was obtained with poly (Proline), followed 7 by poly (Alanine). They are both hydrophobic, although, the side chain of poly (Proline) is larger 8 than the Alanine side chain. The yield achieved for poly (Serine) microspheres was the lowest. 9 All poly (amino acids) tested present a negative charge.

10 Table 6. Peptide in monolayer, size (Z-average), particle size distribution (PDI), zeta-potential $11(\zeta)$ and stability tests obtained for different poly (amino acids) $(100 \mu \mathrm{M})$, using an 12 aqueous/organic ratio of $60 / 40$

\begin{tabular}{llllll}
\hline $\begin{array}{l}\text { Poly } \\
\text { acids) }\end{array}$ & $\begin{array}{l}\text { Monolayer } \\
\left(\mathrm{n}_{\mathrm{m}}\right)^{[\mathrm{a}]}\end{array}$ & $\begin{array}{l}\text { Yield } \\
{[\%]}\end{array}$ & $\begin{array}{l}\text { Z- } \\
\text { average } \\
{[\mathrm{mg}]}\end{array}$ & PD1 & $\zeta[\mathrm{mV}]$ \\
& $5.11 \pm 0.2$ & $29 \pm 8$ & $796 \pm 27$ & $1 \pm 0.02$ & $-11 \pm 0.8$ \\
\hline Poly (Serine) & $5.32 \pm 0.1$ & $60 \pm 2$ & $690 \pm 16$ & $0.9 \pm 0.03$ & $-31 \pm 0.5$ \\
\hline Poly (Proline) & $4.55 \pm 0.1$ & $50 \pm 2$ & $676 \pm 36$ & $0.8 \pm 0.02$ & $-26 \pm 1$ \\
\hline Poly (Alanine) & 2.551 & - & - & - \\
\hline Poly (Lysine) & - & - & - & & \\
\hline
\end{tabular}

[a] Calculated according with Eq. (2)

14 Following Eq. (2), we compare the sizes of microspheres prepared with different peptides and 15 poly (amino acids). Figures $\mathbf{7}$ and $\mathbf{8}$ demonstrate the importance of the hydrophobic/hydrophilic 16 residue balance in peptide sequence in order to achieve particles with a reduced size. 


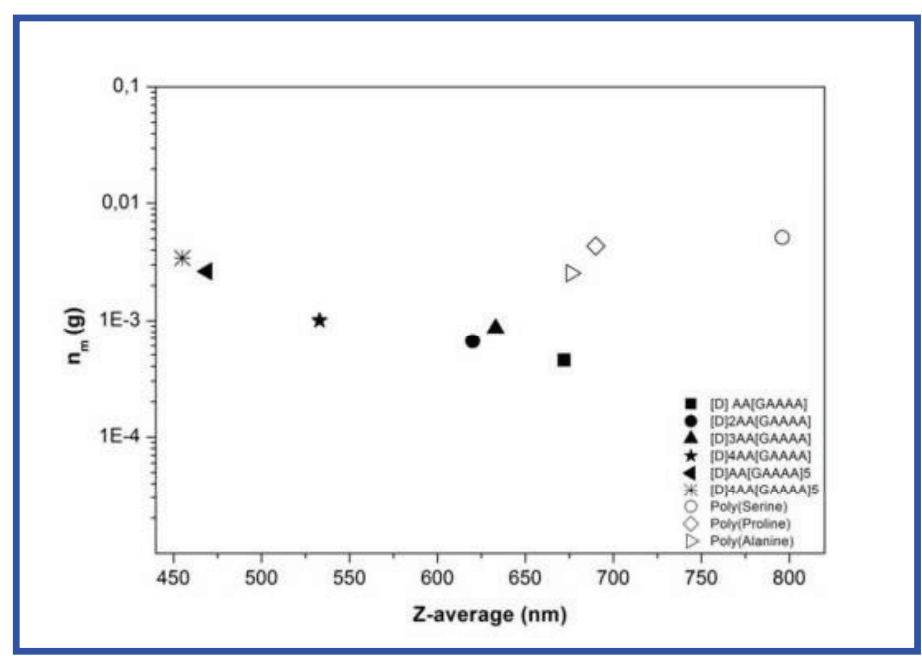

2 Figure 7. Relationship between the peptide, based on fatty acid models, and poly (amino acids)

3 present in the monolayer of microsphere $\left(\mathrm{n}_{\mathrm{m}}, \mathrm{g}\right)$, calculated from Eq. (2) and the size obtained $4 \quad(\mathrm{~nm})$.

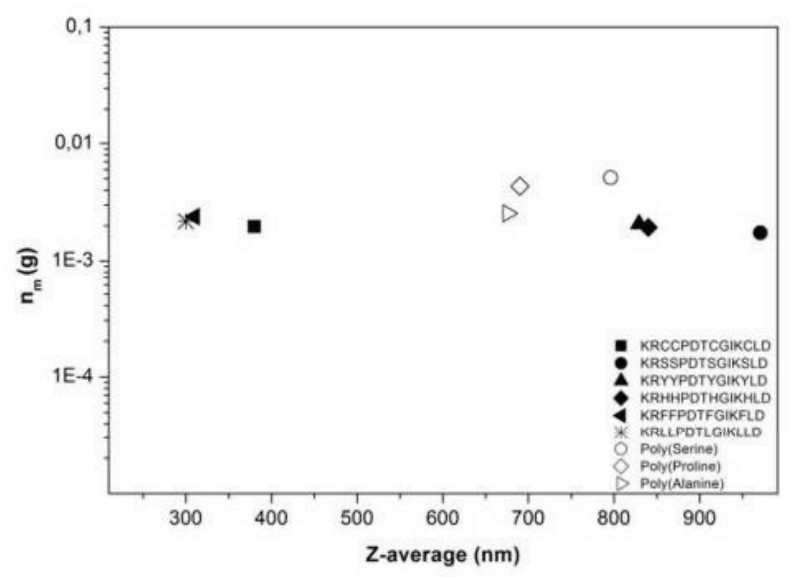

7 Figure 8. Relationship between the peptide, based on SLPI, and poly (amino acids) present in 8 the monolayer of microsphere $\left(\mathrm{n}_{\mathrm{m}}, \mathrm{g}\right)$, calculated from Eq. (2) and the size obtained $(\mathrm{nm})$. 
1 3.3. Proposed mechanism of microsphere formation

2 Proteins are natural macromolecules, generally containing hydrophobic and hydrophilic

3 segments in their structure. In an aqueous phase, proteins form stable 3D structures based on the

4 balance between outer hydrophilic segments covering the inner hydrophobic segments in a 5 conformation of minimal energy. When the high shear forces, such as ultrasound, are applied to 6 the biphasic systems of water/hydrophobic solvent, proteins tend to adapt their structure and 7 migrate to the interface. Depending on the protein structure, its adaptation may include a 3D 8 modification of protein, as is shown here for BSA, where no significant changes were found in 9 their secondary structure. The accommodation of SF to the water/solvent interface tends to 10 promote self-assembly and $\beta$-sheet formation. In all cases, the protein seems to form a shell with 11 hydrophobic characteristics near the organic solvent and hydrophilic characteristics near water 12 (Scheme 1). Our results (Table 2 and 3) suggest that proteins are adsorbed at the interface in a 13 multilayer fashion. Microsphere formation is completely independent of the presence of 14 Cysteine, and the high shear forces are a driving force to achieve stable particles. Smaller and 15 stable particles can be obtained with an high water content and with peptides with clear 16 hydrophobic/hydrophilic sequences. 


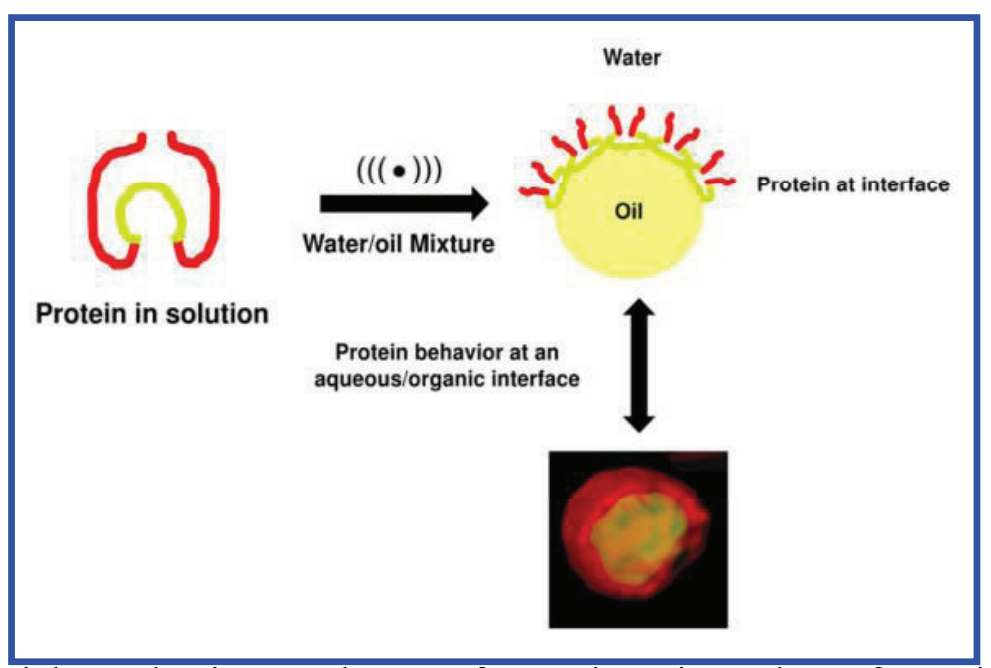

2 Scheme 1: Potential mechanism pathway of protein microsphere formation: 1) protein in

3 solution; 2) protein arrangement at the interface of aqueous/organic phase showing the

4 hydrophilic residues (red color) interacting with water and the hydrophobic residues (green

5 color) interact with the organic phase. Proteins tend to adapt their structure and its adaptation 6 includes a 3D modification of protein.

\section{4. Conclusions}

8 This study aimed at highlighting the effects of ultrasound in the formation of microspheres of

9 different proteins and peptides. Herein, it was established that the amount of protein and the

10 hydrophobic solvent volume fraction are essential parameters for the proteinaceous microsphere 11 process. The use of different synthetic peptides allows us to believe that the right balance of 12 hydrophilic/hydrophobicity is the major issue to control in order to promote microsphere 13 formation, and, consequently, higher stabilization. Gathering all the results it is also possible to 14 conclude that for the particles formation and stabilization there is no need of disulfide bonds, but 15 the presence of hydrophobic and hydrophilic interactions. 
1 This work provides the groundwork for designing the process to achieve stable proteinaceous

2 microspheres. We believe it is possible to build desired particles with specific properties that can

3 be applied in biomedical research field.

4

5

6

7

8

9

10

11

12

13

14

15

16

17

18

19

20

21

22

23

ACS Paragon Plus Environment 


\section{FIGURE CAPTIONS.}

2 Figure 1. STEM photographs (x50000 magnification) of proteinaceous microspheres: (a) BSA

3 and (b) SF obtained with a protein concentration of $5.0 \mathrm{~g} \mathrm{~L}^{-1}$ and $10.0 \mathrm{~g} \mathrm{~L}^{-1}$ for BSA and SF, 4 respectively.

5 Figure 2. Left: Confocal photograph of BSA microspheres colored with Nile red dye (green 6 color shows the more polar regions excited with a laser line of $532 \mathrm{~nm}$, and the red color shows 7 the more nonpolar regions excited with a laser line of $488 \mathrm{~nm}$ ). Right: The 3D image 8 reconstructed from confocal z-stack images using "Imaris" software, 3D evidence of the protein 9 behavior at an aqueous/organic interface, presenting a green color in a less hydrophobic medium, 10 while in a nonpolar solvent it acquires a red color, suggesting a more hydrophobic core in its 11 structure. The few green color points in the core are probably due to the water molecule trapped 12 inside the PMs.

13 Figure 3. Molecular dynamic simulation results of BSA in a $1: 1$ (v:v) mixture of water/n14 dodecane. BSA (green) in the interface water (red and white) $/ n$-dodecane (not shown). The BSA 15 portion that is visible is interacting with $n$-dodecane.

16 Figure 4. Representation of the potential surface in vacuum: left) on the surface of BSA facing 17 the water phase; right) on the surface of BSA that lies on the interface water $n$-dodecane. The 18 potentials were calculated using Pymol.

19 Figure 5.Yield of BSA (left panel) and SF (right panel) microspheres formation using different 20 aqueous/organic ratios $(\% ; 60 / 40 ; 80 / 20$ and $95 / 5)$ and different protein concentrations $(0.1 ; 0.5$; $21 \quad 1.0 ; 5.0 \mathrm{~g} \mathrm{~L}^{-1}$ for BSA and 3.0; 5.0; $10.0 \mathrm{~g} \mathrm{~L}^{-1}$ for $\mathrm{SF}$ ). 
1 Figure 6. Relationship between the protein present in the monolayer of microsphere $\left(\mathrm{n}_{\mathrm{m}}, \mathrm{g}\right)$,

2 calculated from Eq. (2) and the size obtained (nm).

3 Figure 7. Relationship between the peptide, based on fatty acid models, and poly (amino acids)

4 present in the monolayer of microsphere $\left(\mathrm{n}_{\mathrm{m}}, \mathrm{g}\right)$, calculated from Eq. (2) and the size obtained $5(\mathrm{~nm})$.

6 Figure 8. Relationship between the peptide, based on SLPI, and poly (amino acids) present in 7 the monolayer of microsphere $\left(\mathrm{n}_{\mathrm{m}}, \mathrm{g}\right)$, calculated from Eq. (2) and the size obtained (nm).

8 SCHEME TITLES.

9 Scheme 1: Potential packing pathway of protein microsphere formation: 1) protein in solution; 10 2) protein arrangement at the interface of aqueous/organic phase showing the hydrophilic 11 residues (red color) interacting with water and the hydrophobic residues (green color) interact 12 with the organic phase. Proteins tend to adapt their structure and its adaptation includes a 3D 13 modification of protein.

14 TABLES.

15 Table 1. Results from the curve fitting of the Amide I range of the FT-IR spectrum of 16 proteinaceous microspheres prepared with $5.0 \mathrm{~g} \mathrm{~L}^{-1}$ of BSA and $10.0 \mathrm{~g} \mathrm{~L}^{-1}$ of SF, using $60 / 40$ of 17 aqueous/organic ratio

18 Table 2. Protein in monolayer, size (Z-average), particle size distribution (PDI) and stability 19 tests at the end of 4 months, obtained for the BSA protein $\left(5.0 \mathrm{~g} \mathrm{~L}^{-1}\right)$

20 Table 3. Protein in monolayer, size (Z-average), particle size distribution (PDI) and stability 21 tests at the end of 4 months, obtained for the SF protein $\left(5.0 \mathrm{~g} \mathrm{~L}^{-1}\right)$ 
1 Table 4. Peptide in monolayer, size (Z-average), particle size distribution (PDI), zeta-potential

$2(\zeta)$ and stability tests obtained for the engineered peptides based on fatty acid model $(100 \mu \mathrm{M})$,

3 using an aqueous/organic ratio of $60 / 40$

4 Table 5. Peptide in monolayer, size (Z-average), particle size distribution (PDI), zeta-potential

$5(\zeta)$ and stability tests obtained for the engineered peptides based on SLPI sequence, $(100 \mu \mathrm{M})$,

6 using an aqueous/organic ratio of $60 / 40$

7 Table 6. Peptide in monolayer, size (Z-average), particle size distribution (PDI), zeta-potential

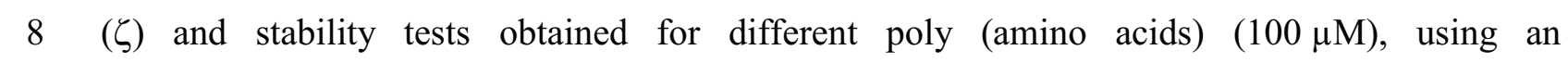
9 aqueous/organic ratio of $60 / 40$ 


\section{ASSOCIATED CONTENT}

2 Supporting Information. Additional information including SF and peptide sequence details and

3 FT-IR spectrum of protein microspheres. This material is available free of charge via the Internet

4 at http://pubs.acs.org.

5

\section{AUTHOR INFORMATION}

\section{Corresponding Author}

8 *University of Minho, Department of Textile Engineering, Campus de Azurém, 4800-058,

9 Guimarães, Portugal, artur @det.uminho.pt, Tel: 00351253 510271, Fax: 00351253510293

\section{Author Contributions}

11 The manuscript was written through contributions of all authors. All authors have given approval 12 to the final version of the manuscript.

\section{Funding Sources}

14 This work was supported by Lidwine Project-Multifunctional medical textiles for wound (e.g.

15 Decubitus) prevention and improved wound healing NMP2-CT-2006-026741 and by POPH/FSE

16 a co-financing and FCT for Fellowship SFRH/BPD/38939/2007.

\section{ACKNOWLEDGMENT}

18 This work was supported by Lidwine Project-Multifunctional medical textiles for wound (e.g.

19 Decubitus) prevention and improved wound healing NMP2-CT-2006-026741. Helena Ferreira 20 thanks POPH/FSE for co-financing and FCT for Fellowship SFRH/BPD/38939/2007. The 


\section{Page 33 of 36}

\section{Molecular Pharmaceutics}

1 authors want to knowledge Silvia Cappellozza from "Sezione Specializzata per la Bachicoltura"

2 for the supply of silk cocoons.

3

4

5

6

7

8

9

10

11

12

13

14

15

16

17

18

19

20

21

22

23

24

25

26

ACS Paragon Plus Environment 


\section{REFERENCES}

1. Branco, M. C.; Schneider, J. P., Self-Assembling Materials for Therapeutic Delivery. Acta Biomater. 2009, 5, (3), 817-831.

2. Vauthey, S.; Santoso, S.; Gong, H.; Watson, N.; Zhang, S., Molecular Self-Assembly of Surfactant-Like Peptides to form Nanotubes and Nanovesicles. Proc. Natl. Acad. Sci. USA 2002, 99, (8), 5355-5360.

3. Childers, W. S.; Ni, R.; Mehta, A. K.; Lynn, D. G., Peptide Membranes in Chemical Evolution. Curr. Opin. Chem. Biol. 2009, 13, (5-6), 652-659.

4. Suslick, K. S.; Grinstaff, M. W., Protein Microencapsulation of Nonaqueous Liquids. J. Am. Chem. Soc. 1990, (112), 7807-7809.

5. Grinstaff, M. W.; Suslick, K. S., Nonaqueous Liquid Filled Microcapsules. Polymer Preparation 1991, 32, 255.

6. $\quad$ Grinstaff, M. W.; Kolbeck, K. A.; Magin, R. L.; Suslick, K. S.; Webb, A.; Wilmes, L. J.; Wong, M.; Desai, N. P.; Sandford, P. A.; Soon-Shiong, P., Proc. Soc. Biomaterial 1994, 20, 113. 7. $\quad$ Suslick, K. S.; Grinstaff, M. W., Proc. Natl. Acad. Sci. USA 1991, 88, 7708.

8. Wong, M.; Suslick, K. S., Sonochemically Produced Hemoglobin Microbubbles. Mater. Res. Soc. Symp. Proc. 1995, 372, 89.

9. Suslick, K. S.; Grinstaff, M. W.; Kolbeck, K. J.; Wong, M., Characterization of Sonochemically Prepared Proteinaceous Microspheres. Ultrason. Sonochem. 1994, 1, (1), S65S68.

10. Mason, T. J.; Lorimer, J. P.; Bates, D. M.; Zhao, Y., Dosimetry in sonochemistry: the use of aqueous terephthalate ion as a fluorescence monitor. Ultrason. Sonochem. 1994, 1, (2), 91-95.

11. Suslick, K. S.; Price, G. J., Applications of Ultrasound to Materials Chemistry. Annu. Rev. Mater. Res. 1999, (29), 295-326.

12. Rae, J.; Ashokkumar, M.; Eulaerts, O.; von Sonntag, C.; Reisse, J.; Grieser, F., Estimation of ultrasound induced cavitation bubble temperatures in aqueous solutions. Ultrason. Sonochem. 2005, 12, (5), 325-329.

13. Little, C.; El-Sharif, M.; Hepher, M. J., The effect of solution level on calorific and dosimetric results in a $70 \mathrm{kHz}$ tower type sonochemical reactor. Ultrason. Sonochem.2007, 14, (3), 375-379.

14. Avivi, S.; Gedanken, A., S-S bonds Are Not Required For The Sonochemical Formation of Proteinaceous Microspheres: The Case of Streptavidin. Biochem. J. 2002, 366, (3), 705-707.

15. Peters, T. J., Serum Albumin. Adv. Protein Chem. 1985, 37, 161-245.

16. Yamaguchi, K.; Kikuchi, Y.; Takagi, T.; Kikuchi, A.; Oyama, F.; Shimura, K.; Mizuno, S. J., J. Mol. Biol. 1989, 210, (1), 127-139.

17. Lotz, B.; Colonna, F. C., Biochimie 1979, 61, 205-214.

18. Ashcroft, G. S.; Lei, K.; Jin, W.; Longenecker, G.; Kulkarni, A. B.; Greenwell-Wild, T.; Hale-Donze, H.; McGrady, G.; Song, X.-Y.; Wahl, S. M., Secretory Leukocyte Protease Inhibitor Mediates Non-Redundant Functions Necessary for Normal Wound Healing. Nat Med 2000, 6, (10), 1147-1153.

19. Lowry, O. H.; Rosebrough, N. J.; A. Lewis Farr; Randall, R. J., Protein Measurement with Folin-Phenol Reagent. J. Biol. Chem. 1951, 193, (1), 265-275.

20. Bunjes, H., Characterization of Solid Lipid Nanoparticles and Microparticle. In Lipospheres in Drug Targets and Delivery Approaches, Methods and Applications, Nastruzzi, C., Ed. CRC Press LLC: Boca Raton, Florida, 2005; pp 41-66. 
21. Anandan, S.; Yoon, M., Photoinduced Electron Transfer Studies of Nile Red in the Presence of TiO2 Colloidal Nanoparticles. Spectro. Chim. Acta A 2004, 60, (4), 885-888.

\section{J. Lipid Res. 1985, 26, 781-789.}

23. Haris, P. I.; Severcan, F., FTIR Spectroscopic Characterization of Protein Structure in Aqueous and Non-Aqueous Media. J. Mol. Catal. B: Enzym. 1999, 7, (1-4), 207-221.

24. Chittur, K. K., FTIR/ATR for Protein Adsorption to Biomaterial Surfaces. Biomaterials 1998, 19, (4-5), 357-369.

25. Byler, D. M.; Susi, H., Examination of the Secondary Structure of Proteins by Deconvolved FTIR Spectra. Biopolymers 1986, 25, 469-487.

26. Dong, A.; Huang, P.; Caughey, W. S., Protein Secondary Structures in Water from Second-Derivative Amide I Infrared Spectra. Biochemistry 1990, 29, (13), 3303-3308.

27. Kong H.; Ye F.; Lu X.; Guo L.; Tian J.; G., X., Deconvolution of Overlapped Peaks Based on the Exponentially Modified Gaussian Model in Comprehensive Two-Dimensional Gas Chromatography J. Chromatogr., A 2005, 1086, (1-2), 160-164.

28. Gülseren, I.; Güzey, D.; Bruce, B. D.; Weiss, J., Structural and Functional Changes in Ultrasonicated Bovine Serum Albumin Solutions. Ultrason. Sonochem. 2007, 14, (2), 173-183.

29. Yampolskaya, G. P.; Tarasevich, B. N.; Elenskii, A. A., Secondary Structure of Globular Proteins in Adsorption Layers at the Solution-Air Interface by the Data of Fourier Transform IR Spectroscopy. Colloid Journal 2005, 67, (3), 385-391.

30. Fu, K.; Griebenow, K.; Hsieh, L.; Klibanov, A. M.; Robert, L., FTIR Characterization of the Secondary Structure of Proteins Encapsulated within PLGA Microspheres. J. Controlled Release 1999, 58, (3), 357-366.

31. Takeda, K.; Shigeta, M.; Aoki, K., Secondary Structures of Bovine Serum Albumin in Anionic and Cationic Surfactant Solutions. J. Colloid Interface Sci. 1987, 117, (1), 120-126.

32. Vasconcelos, A.; Freddi, G.; Cavaco-Paulo, A., Biodegradable Materials Based on Silk Fibroin and Keratin. Biomacromolecules 2008, 9, (4), 1299-1305.

33. Hess, B.; Kutzner, C.; van der Spoel, D.; Lindahl, E., GROMACS 4: Algorithms for Highly Efficient, Load-Balanced, and Scalable Molecular Simulation. J. Chem. Theory Comput. 2008, 4, (3), 435-447.

34. Oostenbrink, C.; Villa, A.; Mark, A. E.; Van Gunsteren, W. F., A Biomolecular Force Field Based on the Free Enthalpy of Hydration and Solvation: The GROMOS Force-Field Parameter Sets 53A5 and 53A6. Journal of Comput. Chemist. 2004, 25, 1656-1676.

35. Feng, S.-S.; Huang, G., Effects of Emulsifiers on the Controlled Release of Paclitaxel (Taxol ${ }^{\circledR}$ ) from Nanospheres of Biodegradable Polymers J. Controlled Release 2001, 71, (1), 53 69.

36. Bala, I.; Hariharan, S.; Kumar, M. N., PLGA Nanoparticles in Drug Delivery: The State of the Art. Crit Rev Ther Drug Carrier Syst 2004, 21, (5), 387-422.

37. Bala, I.; Bhardwaj, V.; Hariharan, S.; Sitterberg, J.; Bakowsky, U.; Kumar, M. N. V. R., Design of Biodegradable Nanoparticles: A Novel Approach to Encapsulating Poorly Soluble Phytochemical Ellagic Acid. Nanotechnology 2005, 16, 2819-2822. 
1 SYNOPSIS. The high shear forces produced by ultrasound allow a conformational change of

2 proteins, promoting microsphere formation. These forces lead to the orientation of polar and

3 non-polar groups of proteins in a biphasic system. Proteins tend to adapt their structure and its

4 adaptation includes a 3D modification of protein. Herein, we offer new insights onto the

5 mechanisms of the formation of PMs.

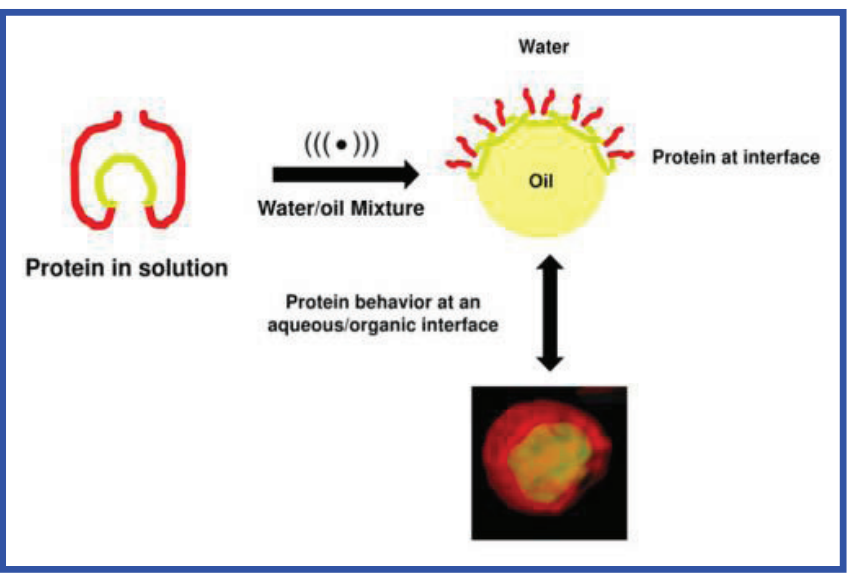

6

8

9 